\title{
Incorporating enhanced service reliability of public transport in cost-benefit analyses
}

\author{
N. van Oort ${ }^{1}$
}

Published online: 1 March 2016

(C) The Author(s) 2016. This article is published with open access at Springerlink.com

\begin{abstract}
In this paper, we demonstrate how to calculate the passenger impacts of service unreliability. We show that passengers are affected by longer waiting times and the distribution of travel times. We present a framework to calculate these effects and to express them in monetary values. In the Netherlands and many other countries, service reliability is not explicitly incorporated in cost benefit analyses, although improved service reliability is often one of the main contributions of public transport projects. In an actual case, the replacement of a bus line by a tram line in Utrecht, in The Netherlands, we proved that our framework is valuable and can be applied into practice. By calculating the benefits of the improved service reliability of the proposed tram line, which were about $2 / 3$ of all benefits, the cost benefit ratio was positive, which convinced the Dutch Minister of Infrastructure and Environment to support the project by $€ 110$ million.
\end{abstract}

Keywords Cost benefit analysis - Service reliability · Tram line planning

\section{Introduction}

In the last decade, more attention has been paid to service reliability. Service reliability is an important quality characteristic in public transport. Both passengers and operators benefit from enhanced service reliability by decreased and predictable travel times, and by lower costs, respectively. Van Oort (2011) provides an overview of several measures to improve the level of service reliability, at all levels of public transport planning and operations. However, in cost-benefit analyses

N. van Oort

NvOort@Goudappel.nl

1 Goudappel Coffeng Mobility Consultants/Delft University of Technology, PO Box 5048, 2600 GA Delft, The Netherlands 
(CBA, a method to quantify and clarify the cost-effectiveness of projects, see, for instance, Johanssen 1991, Annema et al. 2007 and Li et al. 2010), this quality aspect is rarely taken into account explicitly. Figure 1 shows the results of a quick scan of over 20 randomly selected CBAs of public transport projects in the Netherlands. We reviewed them concerning the incorporation of reliability impacts. It is demonstrated that the attention to calculating service reliability effects is limited. Most of the time, a qualitative assessment or expert judgement is used, while proper calculations would be more appropriate since most public transport projects aim at improving service reliability.

In both OECD/ITF (2009) and Li et al. (2010), developments concerning CBAs and reliability all over the world are presented. It is stated that incorporating reliability in CBAs is only applied in a limited number of countries such as United Kingdom, the Netherlands, Denmark, New Zealand, Australia, Norway and Sweden. However, the main applications are focussing on road traffic instead of public transport.

One of the main reasons for ignoring reliability impacts in CBAs, is that it is hard to quantify service reliability effects of projects on passengers. In general, the focus of service reliability indicators is often on vehicle effects (Van Oort 2011), while the passenger effects are of importance when calculating costs and benefits.

In this paper, we present a method to calculate these effects and to incorporate them into a cost benefit analysis. Recent research (Van Oort 2011) enables proper analysis of service reliability with regard to passengers. This method is applied to the case study of a new tram line in the city of Utrecht (over 300,000 inhabitants) in the centre of The Netherlands. To provide seamless transport, this tram line connects the central station in Utrecht with the university and the hospital. To provide a proper alternative to car traffic, high quality of service is necessary. High service reliability is one of the main objectives in this project.

This case demonstrates that service reliability may be a substantial benefit of a public transport project and it shows the possibilities of incorporating service reliability effects effectively in a CBA. This project successfully connects the results of a PhD research (Van Oort 2011) to a practical project, namely the tram project in Utrecht. This project is a first step to harmonizing standards in CBAs concerning service reliability effects.

Fig. 1 Results of survey on incorporating service reliability impacts in Dutch CBAs

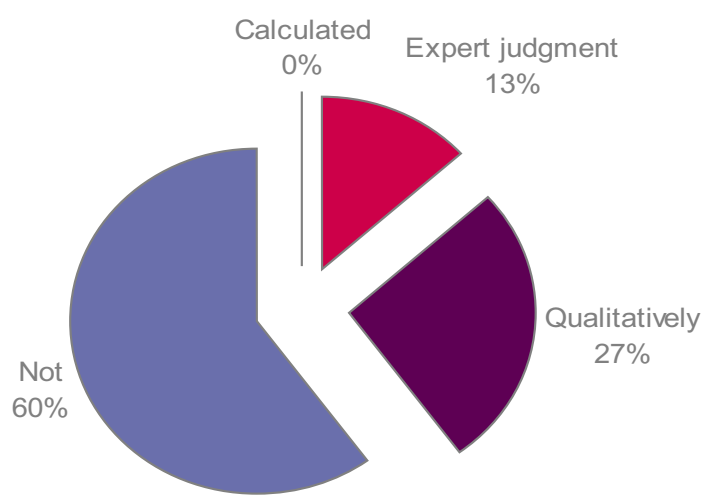




\section{Service reliability effects on passengers}

\subsection{Service reliability}

We define service reliability as the certainty of service aspects compared to the schedule (such as travel time (including waiting), arrival time and seat availability) as perceived by the user. Service variability is defined as the distribution of output values of the supply side of public transport, such as vehicle trip time, vehicle departure time and headways. In our research, we mainly focus on the travel time impacts. Service reliability is one of the main quality aspects of public transport and is often at a poor level. Improved service reliability increases the overall quality of public transport, thereby ensuring accessible and liveable cities for future generations and reducing the growth of car mobility.

In literature, much research is available with regard to passenger choices as a function of service reliability. Bates et al. (2001) and Rietveld et al. (2001) state that service reliability of public transport systems has been considered critically important by most public transport users because passengers are adversely affected by the consequences associated with unreliability such as additional waiting time, late or early arrival at destinations and missed connections, which increases their anxiety and discomfort. Route choice might be affected by unreliability, as presented by Abdel-Aty et al. (1994), Schmöcker and Bell (2002) and Liu and Sinha (2007). Service reliability is also been identified as important in determining the mode choice (Turnquist and Bowman 1980). Therefore, it may be stated that unreliability in public transport drives away existing and prospective passengers.

\subsection{Impacts of service unreliability}

In preparation of quantifying service reliability, this section demonstrates the impacts of service reliability on passengers. The passenger mainly experiences the following three effects (Noland and Small 1995; Noland and Polak 2002; Van Oort and Van Nes 2009; note that due to the stochastic nature, the impacts on individual passengers may differ from average values).

- Impacts on duration of travel time components, being in-vehicle time and waiting time, which lead to early or late arrival;

- Impacts on variability of travel time components, being departure time, arrival time, in-vehicle time and waiting time, which lead to uncertainty of the actual travel time;

- Impact on probability of finding a seat and crowding, which affects the level of comfort of the journey.

This paper focuses on the first two aspects, namely the travel time related aspects. More detailed research on crowding may be found, for instance, in Hensher et al. (2011). 
To calculate the passenger effects of unreliability, it is important to gain insights into the quality of service of public transport operations. This consists of characteristics of the service supply, such as actual departure times per stop, actual dwell times, actual headways and actual trip times. In the calculation of service reliability effects, this vehicle related data (available by Automated Vehicle Location (AVL)-systems or forecast tools such as illustrated in Kanacilo and Van Oort 2008) is translated into passenger effects, using Automated Passenger Counter (APC) data. Figure 2 illustrates both the demand and supply sides and the link of vehicle trip elements with the passenger journey elements. Note that a relationship also exists in the other direction. Dwell time, for instance, is strongly affected by passenger behaviour. Passenger waiting time is determined by actual headways and departure times as well as passenger arrival time at the stop. Passenger in-vehicle time is equal to the trip time of the vehicle and sets the arrival time at the destination, in combination with the departure time. If a passenger makes a transfer, a new waiting time for the passenger will arise. This new waiting time is affected by the planned synchronization between the two connecting vehicles, the actual performance of this synchronization and the waiting regime of the connecting vehicle. In this paper, we provide equations to translate vehicle characteristics into passenger effects in a single line case. This relationship depends on the arrival pattern of passengers at their departure stop. An extension of this approach towards incorporating transfers is presented in Lee et al. (2014).

In this paper, we only investigate high frequent public transport systems. In a survey (Van Oort 2014), we concluded that passengers tend to arrive at random if headways are $10 \mathrm{~min}$ or less. This conclusion supports earlier findings of O'Flaherty and Mangan (1970) and Seddon and Day (1974) who stated that passengers arrive at random if scheduled headways are shorter than 10-12 min. In the case of random arrival of passengers at their first stop, the additional waiting time of passengers is determined by the headway variation (Welding 1957; Osuna and Newell 1972; Heap and Thomas 1976).

The main conclusion is thus that service reliability effects on passengers are affected by both vehicle and passenger-related aspects. The next section will present a framework that supports calculating these effects. In our research we focused on

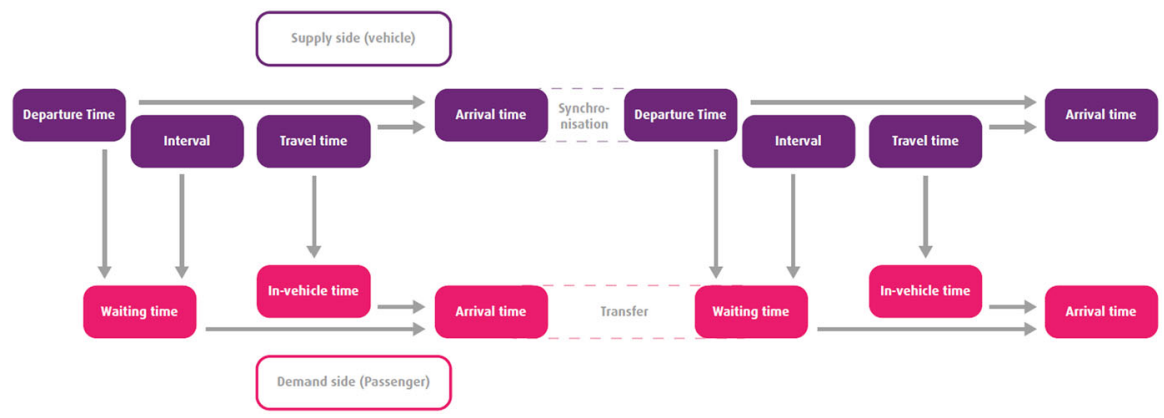

Fig. 2 (Interaction of) passenger trip chain (below) and vehicle characteristics (above) 
single lines. The following step is research on the total trip chain, including transfers (Lee et al. 2014).

\subsection{Calculating service reliability effects}

In order to improve service reliability it is essential to monitor and predict the level of service reliability of a public transport system. For this we need proper indicators. The commonly used indicators, which are supposed to express reliability, do not completely focus on the passenger impacts of service reliability. In fact, they focus more on service variability of the system (and the deviation of the schedule) than on the actual impacts on passengers. Well-known examples of supply side indicators are punctuality (indicating the level of schedule deviation) and regularity (indicating the level of headway deviation; Van Oort 2011). However, the previous section demonstrated the importance of taking the demand side into account while assessing service reliability. This section introduces a new indicator enabling enhanced quantifying of service reliability. This new indicator is the basis for quantifying service reliability effects in a CBA.

Although the supply-side indicators often help to illustrate the level of service provided to the passenger, they do not completely match the customer perception. Vehicles driving ahead or being late for example affect passenger travel time in a completely different way. The arrival pattern of passengers at the stop where they depart is of importance to determine the impacts for the passenger. If passengers arrive at random (for instance, in case of short-headway services when no exact timetable is provided), the deviation from the schedule is not relevant anymore. Passenger waiting time is then minimized (i.e. on average half the scheduled headway) if actual headways are constant (Welding 1957; Osuna and Newell 1972; Heap and Thomas 1976). If passengers use the schedule to plan their moment of arrival at their departure stop, the deviation from the timetable is important. However, in this paper we do not investigate that case, since we focus on highfrequent operations. Van Oort et al. (2012) provide more insights in low-frequent public transport operations and the impacts of unreliability on passengers. In addition to the mentioned time effects, the type of stop and availability of (real time) information also affect customer perception of the level of service, but these issues are beyond the scope of this paper.

Service variability may lead to an extension of passenger average travel time, since average waiting time per passenger may be extended due to irregular, early or late vehicles. To express this effect of service variability on passengers more effectively than punctuality and regularity, we introduced a new indicator, called average additional travel time per passenger (Van Oort and Van Nes 2009). In addition to the extension of travel times, the second effect of service variability is the distribution of passenger travel times, which will be described in this section as well. To account for passenger impacts in CBAs, both effects should be considered, being the extension and variation of travel times. In our quick scan mentioned in the introduction, we found that in practice one or both of these effects are often neglected. Our hypothesis is that this is due to both the lack of knowledge and relevant (passenger) data. 
Figure 3 illustrates the average additional travel time per passenger $\left(\mathrm{T}^{\text {add }}\right)$ and the variability of actual travel time relative to the (average) scheduled travel time. It is important to note that $\mathrm{T}^{\mathrm{journey}, \text { sched }}$ consists of the scheduled waiting time and the scheduled in-vehicle time. The latter is directly related to the scheduled vehicle trip time and is thus controllable being a function of schedule design (e.g. tight or loose schedule). In our calculations, we will focus on the average passenger in-vehicle time and only account for additional in-vehicle time if the variability is adjusted during the operations (e.g. by vehicle holding (Delgado et al. 2012). Note that in case of random passenger arrival at the departure stop, the scheduled waiting time consists of a distribution (with a value between 0 and the schedule headway). On average however, scheduled waiting time equals half the headway. During the planning of their trip (using journey planners, for instance), passengers will perceive their scheduled travel time as fixed (as illustrated by a Dutch survey by Bos 2013). In our framework, we assume this as the reference travel time.

Figure 4 illustrates the phenomenon of additional travel time using an example of a single passenger journey. In a situation without service variability (Fig. 4a), the travel time consists of access time, waiting time, in-vehicle and egress time. Again, waiting time is not fixed in case of random arrivals, but a distribution between 0 and the scheduled headway. In the case where service variability arises, passenger waiting time depends on the arrival pattern of passengers and the level of regularity and schedule adherence. In-vehicle time is determined by the scheduled vehicle trip time and access and egress times are a result of line and stop spacing.

Due to variability in actual vehicle trip times and corresponding deviations of scheduled vehicle departure times and headways, waiting times at stops will on average increase per passenger, leading to longer travel times than the scheduled travel time. An example of this extended travel time is shown by Fig. 4b. Access and egress times are not directly affected by variability in operations. In-vehicle time is affected by this variability as well, but this may result in an extension of travel time for some passengers (as shown by Fig. 4c) and a decrease for others. The net effect depends on the scheduled trip time (tight or loose schedule). So, the reference (the scheduled trip time) is of importance whether a delay will occur (or earliness). If vehicle trip time variability is fixed, no additional average in-vehicle time per passenger will arise. Only when instruments or design choices affect this distribution (e.g. vehicle holding), the additional in-vehicle time is relevant. After

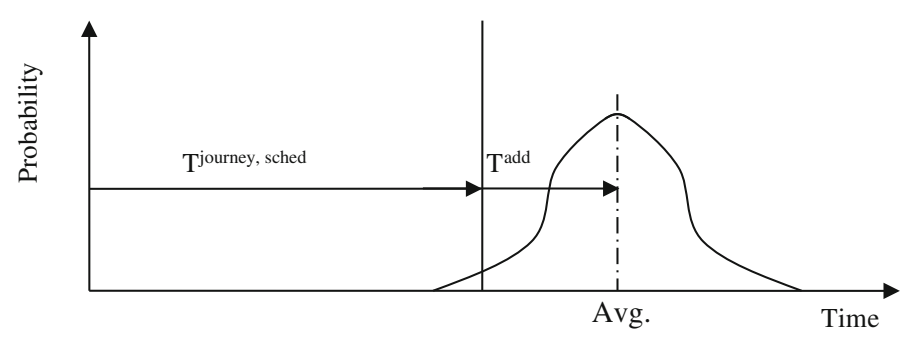

Fig. 3 Scheduled average passenger journey time $\left(\mathrm{T}^{\text {journey, sched }}\right)$, average additional travel time per passenger $\left(\mathrm{T}^{\text {add }}\right)$ and distribution 


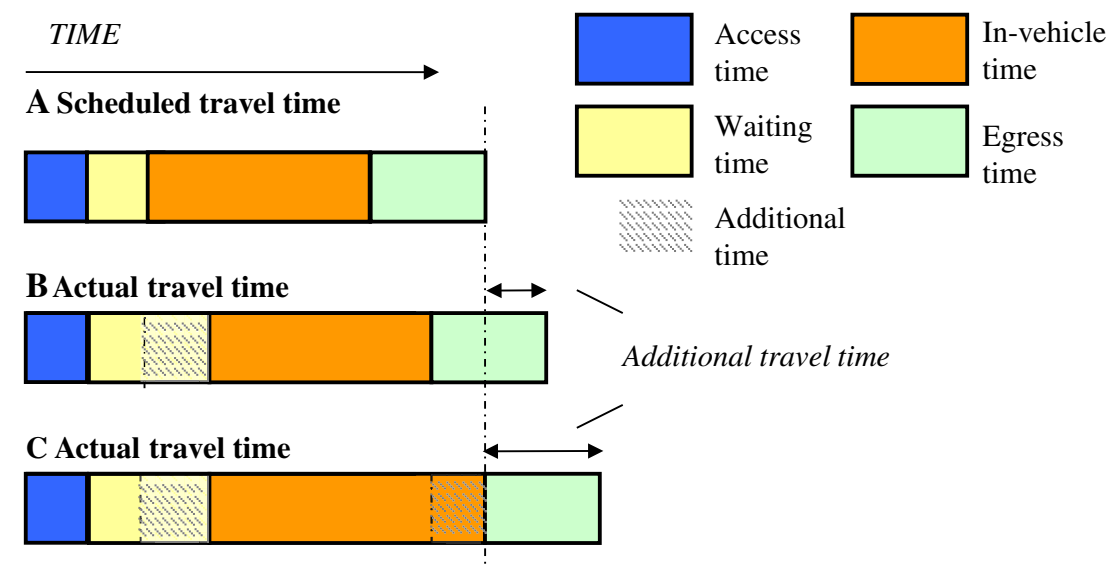

Fig. 4 Scheduled travel time and additional travel time (illustrated using an example of an individual passenger journey)

calculating all individual additional travel times, the final indicator, the average additional travel time per passenger and its distribution may be calculated.

Using the average additional travel time per passenger as an unreliability impact indicator, the focus on quantifying service reliability shifts from the supply side (variability) to the impacts on the demand side. Using this indicator, increase or decrease of average total travel time due to changes in service variability may be properly expressed, enabling analyses of introducing new instruments and comparing several network designs and timetable proposals in, for instance, CBAs. At this moment, proper expressing of passenger reliability benefits is hardly possible (Snelder and Tavasszy 2010). The additional travel time indicator also enables to deal properly with the trade-off between speed and service reliability (as also discussed by Furth and Muller 2009). Using supply-oriented indicators would lead to a focus on the match between schedule and operations which might lead to suboptimal timetables. For instance, the timetable is the reference indicating the match and decreasing the speed in the timetable might improve this match. As schedules (and operations) might become slow, it is obvious that this will not necessarily lead to an increase in overall service quality.

Additional travel time is not commonly used in practice. An international survey (Van Oort 2014) showed that only London seems to use a comparable indicator: excess journey time (Frumin et al. 2009; Uniman 2009). This indicator also expresses the additional travel time due to unreliability, but it compares actual and free-flow travel times instead of actual and scheduled travel times. This paper shows a first application of our new indicator with promising results. Further research is ongoing to sophisticate our framework and its applications.

When calculating the additional travel time, two situations have to be distinguished, namely planned and random arrivals of passengers at the stop. If passengers arrive at random, exact departure times and punctuality are not relevant anymore. In general, passengers do not use any schedule anymore for their arrival 
time at the first stop. Sometimes, operators do not even provide departure times; they just show the headway during different time periods. This paper continues describing additional travel time regarding random arrival patterns. The main assumptions in the calculations are:

- The examined period is homogeneous concerning scheduled departure times, trip times and headways (for instance, rush-hour on working days in a month);

- The passenger pattern on the line is assumed to be fixed;

- All passengers are able to board to the first arriving vehicle.

The next step in our research will be extending the model by relaxing the last assumption. Especially in the case of very unreliable and crowded public transport lines passengers are not always able to board the first vehicle. Trozzi et al. (2013) present promising insights concerning this topic. Earlier work on this topic is presented by, for instance, De Cea and Fernandez (1993) and Kurauchi et al. (2003). However, the framework presented in this paper does not yet take this into account.

If passengers arrive at the stop at random, the additional waiting time is calculated using the coefficient of variation $(\mathrm{CoV})$ of the actual headways $\left(\tilde{H}_{l, j}^{a c t}\right)$. A generic formulation for the expected waiting time per passenger is given by Eq. (1) (Welding 1957; Osuna and Newell 1972; Heap and Thomas 1976), given the assumptions mentioned above.

$$
E\left(\tilde{T}_{l, j}^{\text {waiting }}\right)=\frac{E\left(\tilde{H}_{l, j}^{a c t}\right)}{2} \times\left(1+\operatorname{CoV}^{2}\left(\tilde{H}_{l, j}^{a c t}\right)\right)
$$

where, $\tilde{T}_{l, j}^{\text {waiting }}$ is the passenger waiting time on line 1 at stop $\mathrm{j}, \tilde{H}_{l, j}^{a c t}$ is the actual headway of line 1 at stop $\mathrm{j}$, and $\operatorname{CoV}\left(\tilde{H}_{l, j}^{a c t}\right)$ is the coefficient of variation of actual headways of line 1 at stop $\mathrm{j}$.

If the service is regular, the covariance equals zero and the average waiting time will be equal to half the headway. In the case of irregular service, the additional waiting time may then be calculated using Eq. (2). Assuming no change in the actual vehicle trip times, the total average additional travel time per passenger will be equal to the average additional waiting time per passenger.

$$
E\left(\tilde{T}_{l, j}^{\text {Add,waiting }}\right)=\frac{E\left(\tilde{H}_{l, j}^{a c t}\right)}{2} \times\left(\operatorname{CoV}^{2}\left(\tilde{H}_{l, j}^{a c t}\right)\right)
$$

where, $E\left(\tilde{T}_{l, j}^{A d d, \text { waiting }}\right)$ is the average additional waiting time per passenger due to unreliability of line 1 at stop $\mathrm{j}$.

Based on the average additional travel waiting per passenger per stop of a line, we may calculate the average additional waiting time per passenger on the complete line. To do this, the proportion or percentage of boarding passengers per stop is used $\left(\alpha_{l, j}\right)$, as shown by Eq. (3). Please note that using the proportion of passengers makes the indicator independent of the actual number of passengers. 


$$
E\left(\tilde{T}_{l}^{\text {Add,waiting }}\right)=\sum_{j}\left(\alpha_{l, j} \times E\left(\tilde{T}_{l, j}^{\text {Add,waiting }}\right) \quad \text { with } \quad \sum_{j} \alpha_{l, j}=1\right.
$$

where, $\alpha_{l, j}$ is the proportion of passengers of line 1 boarding at stop $\mathrm{j}$.

In addition to the extension of the waiting time, we also calculate the distribution of travel time. In literature, several measures are proposed for describing travel time variability (Turnquist and Bowman 1980; Tseng 2008):

- Coefficient of variation of route travel time $(\mathrm{CoV})$;

- Difference between the 90th and 50th percentile of travel time;

- Difference between the 80th and 50th percentile of travel time.

In this research, we calculated the standard deviation of (additional) travel times, as suggested by, for instance, Turnquist and Bowman (1980), Rietveld et al. (2001) and Tseng (2008), since it is transferrable into monetary values using the value of reliability (Rand and AVV 2005). We applied the equations above in combination with AVL data of the vehicle to calculate the standard deviation of both waiting and in-vehicle times for passengers. When the additional travel time and travel time distributions are calculated, using both vehicle and passenger data, the next step is to express these values in money to incorporate them into a CBA.

\subsection{Incorporating service reliability effects in CBAs}

Service reliability effects are seldom explicitly taken into account in public transport projects. Figure 1 already showed the limited explicit attention in The Netherlands to this phenomenon. In road traffic, more attention is paid to the phenomenon. Snelder and Tavasszy (2010) discussed this issue as well and they state that the method to deal with this in road traffic projects in the Netherlands (i.e. travel time variability gains are assumed to be $25 \%$ of the travel time gains; Besseling et al. 2004) is an underestimation and is very project-specific. Although, similarities exist, application in public transport is more complex since a schedule is involved and a passenger trip chain consists of waiting, transferring, access and egress time in addition to in-vehicle trip time. One of the main reasons to neglect these effects so far is that it is complex to calculate them and much data is needed. However, since methods and data facilitating the calculation of unreliability effects for passengers are available now, it is possible to consider them in a CBA.

The previous section demonstrated how to calculate the passenger effects of service unreliability, namely the additional travel time per passenger and its distribution. Both effects imply disbenefits for both existing and new passengers. Rand and AVV (2005) showed that passengers value a minute standard deviation of travel time $40 \%$ higher than a minute of regular travel time. Table 1 shows both the value of time and value of reliability as used in the Netherlands in 2011. Note that these numbers depend on many factors, such as motive, year and transport mode.

At this moment, much scientific research and public discussion is going on concerning the reduced societal costs for current passengers of enhanced reliability 
Table 1 Value of time and value of reliability in 2011 (Ecorys 2011)

\begin{tabular}{lll}
\hline Travel purpose & Value of time $(/ \mathrm{h})$ & $\begin{array}{l}\text { Value of reliability } \\
(/ \mathrm{h} \text { st.dev })\end{array}$ \\
\hline Business & $€ 10.00$ & $€ 14.00$ \\
Commuter & $€ 17.44$ & $€ 24.42$ \\
Other & $€ 6.33$ & $€ 8.86$ \\
\hline
\end{tabular}

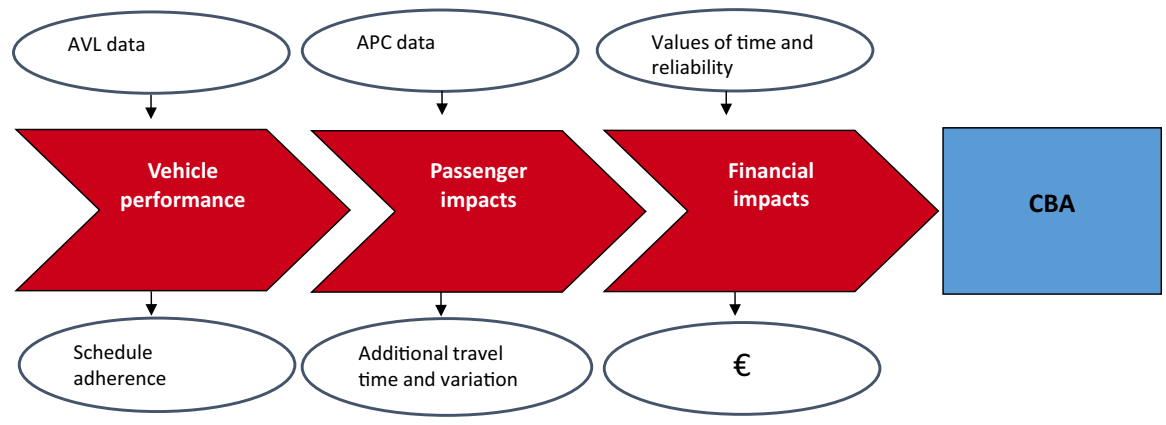

Fig. 5 Three steps to incorporate passenger impacts of service reliability into CBAs

in CBAs. These costs may be calculated using both the value of a unit of travel time extension or variation (P) and the quantity of it (per passenger or summarized; $\mathrm{Q}$ ).

Most research concerning public transport reliability and CBAs (for instance, $\mathrm{Li}$ et al. 2013; Hensher et al. 2011) focuses on the $\mathrm{P}$ (rice) element. The $\mathrm{Q}$ (uantity), for instance, reduction in (standard variation of) travel time, still lacks insights (Van Oort 2011). In contrary to car traffic, where traveller and car are directly connected, calculating the $\mathrm{Q}$ for public transport passengers is complex. In addition to vehicle performance, the timetable and passenger behaviour are relevant. The equations presented in Sect. 2.3 enable the calculation of the quantity concerning both the additional travel time and its variation. In these calculations, the relative weights of different travel time components (e.g. waiting time vs. in-vehicle time) may be incorporated (see, for instance, Van der Waard 1988). These results may be expressed as monetary values by using the values of time and reliability. In that format, they may be directly incorporated into CBAs. Figure 5 summarizes our framework, illustrating the three steps.

\section{Case study: tram line "Uithoflijn"}

\subsection{Introduction}

In addition to setting up a new framework (Fig. 5), we performed a case study in the city of Utrecht in The Netherlands. Utrecht is the fourth largest city in The 
Netherlands with over 300,000 inhabitants. The Dutch government required a CBA to financially support the construction of a tram line in Utrecht between the central station and the Uithof, where the hospital and university are situated.

At this moment the quality of service of the public transport between Utrecht central station and the Uithof is quite poor. Figure 6 shows the current line, which has a total scheduled trip time of approximately $18 \mathrm{~min}$.

Although services are operated by double articulated buses with a scheduled frequency of $23 \times$ per hour per direction, passenger capacity is lacking. On a daily basis, passengers have to wait for two or three buses to board during the peak moments in the rush hour. Only on small parts of the route, own right of way is provided, which leads to conflicts and hindrance with cars and cyclists. This occurs especially at the border of the old town, where space is limited. Due to the interaction with other traffic, busses are delayed all the time and often bunching of two or even three buses occurs. The hindrance and the large amount of passengers using the service result in very unreliable bus operations. The average deviation of the timetable is $4 \mathrm{~min}$ and thus exceeds the scheduled headway (about $2.5 \mathrm{~min}$ ). The line is currently used by about 30,000 passengers per day.

The Uithof is situated in the East of Utrecht, a cluster of knowledge, consisting of the University and other schools, the hospital and several related companies. The plans of the city of Utrecht are to expand this area by $25 \%$. In the end, 53,000 students and 30,000 employees will use this area. Another objective of the city is to handle the growth in mobility by stimulating the usage of bike and public transport. No additional parking lots will be constructed. Demand forecasts (Goudappel Coffeng 2011) show a growth towards 45,000 passengers per day in 2020, which will require over 50 buses an hour per direction to provide adequate capacity. The existing infrastructure is not able to support this number of buses.

To deal with this large increase of public transport use, thereby ensuring high level of service, a new connection was designed. This new line is a fast and reliable connection between the central station and the Uithof. To facilitate reliable services,

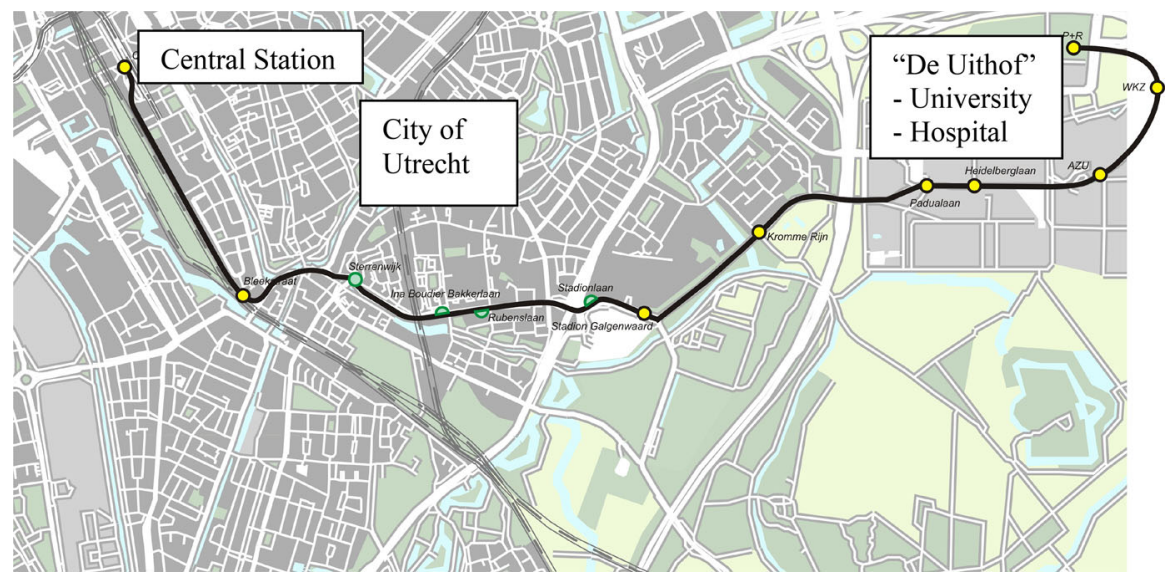

Fig. 6 Current route of bus line Central station-Uithof and vv 
plans are made to shift from bus to tram services. This line is called the Uithoflijn and is shown by Fig. 7. It is about $8 \mathrm{~km}$ long and will operate about $16-20 \times$ per hour per direction during the morning peak.

The main benefit of transferring the bus line into a tram line is, next to less direct emissions, that service can be provided by fewer vehicles than in the case of bus operations (Bunschoten et al. 2013). And since fewer vehicles are needed, the hindrance for crossing traffic (i.e. car and bike traffic) is less, and more importantly, the probability of bunching of vehicles will decrease. However, the construction and operation costs of tramways may be higher than bus operations, especially since Utrecht does not have an extensive rail network that is already available. A CBA is an adequate instrument to gain insights into the details of all the pros and cons, and has been used for this project. The next section will elaborate on the CBA for the Uithoflijn.

\subsection{CBA Uithoflijn}

To construct the tram line, the Dutch ministry of Infrastructure and Environment had $€ 110$ million available. However, the Minister required a positive CBA (indicating a cost-effective project) before supporting this project. The CBA was performed by Ecorys and Goudappel Coffeng (Ecorys 2011; Goudappel Coffeng 2011). In the Netherlands, it is not common practice to incorporate service reliability effects in a CBA, since the algorithms and data were lacking. However, the expectation was that the service reliability effects would play a major role in the CBA of the tram line. We applied our framework presented in Sect. 2 in this project. The focus was on calculating expected reliability-related impacts. Passenger forecasts were provided via the regional transport model (Goudappel Coffeng 2011).

In the CBA of this case, we calculated the service reliability benefits of transferring the existing bus system into a tram system. We compared five future

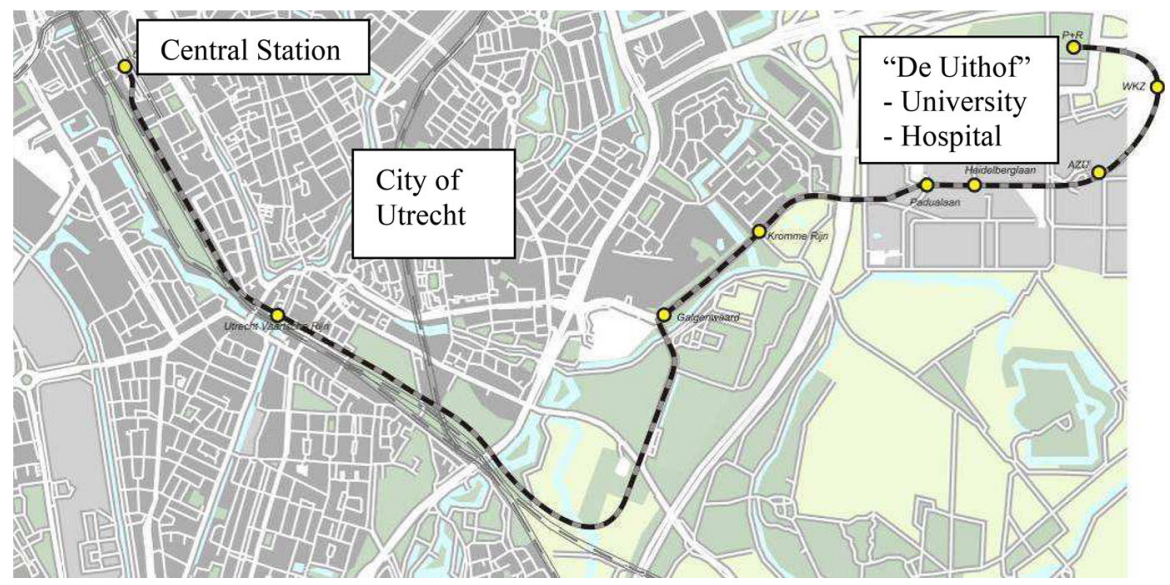

Fig. 7 Proposed route of tram line Central station-Uithof and vv 
situations (in 2020), but in this paper we will only focus on the reference and the preferred alternative. These two cases are described below:

\section{Reference case}

No additional infrastructure will be constructed and the capacity of it is limited. Since ridership will increase and the number of buses accordingly, it is expected that unreliability will increase.

\section{Tram case}

In this case the service is operated by trams with own right of way operations. Due to sufficient capacity on the track and at the stops and little interaction with other traffic, the expected level of service reliability will be high. In addition, compared to the required number of buses (over 50), the number of vehicles is limited, thereby reducing the probability of bunching and delay propagation.

A description of the other alternatives and their costs and benefits may be found in Ecorys (2011).

To support the CBA with insights in the passenger impacts of service reliability, we analysed the actual (2008) performance, which we used as the base for the 2020 predictions. Figure 8 shows the steps of the analysis. The level of service was determined by investigating AVL data. An extensive analysis of the data gained insights into the (distribution of) dwell times per stop, the trip times and the delays. In Van Oort et al. (2015) the Dutch AVL data source and the detailed analyses are presented. APC data was applied to illustrate passenger flows and both data sources were combined using our framework to calculate the passenger impacts of the level of service reliability.

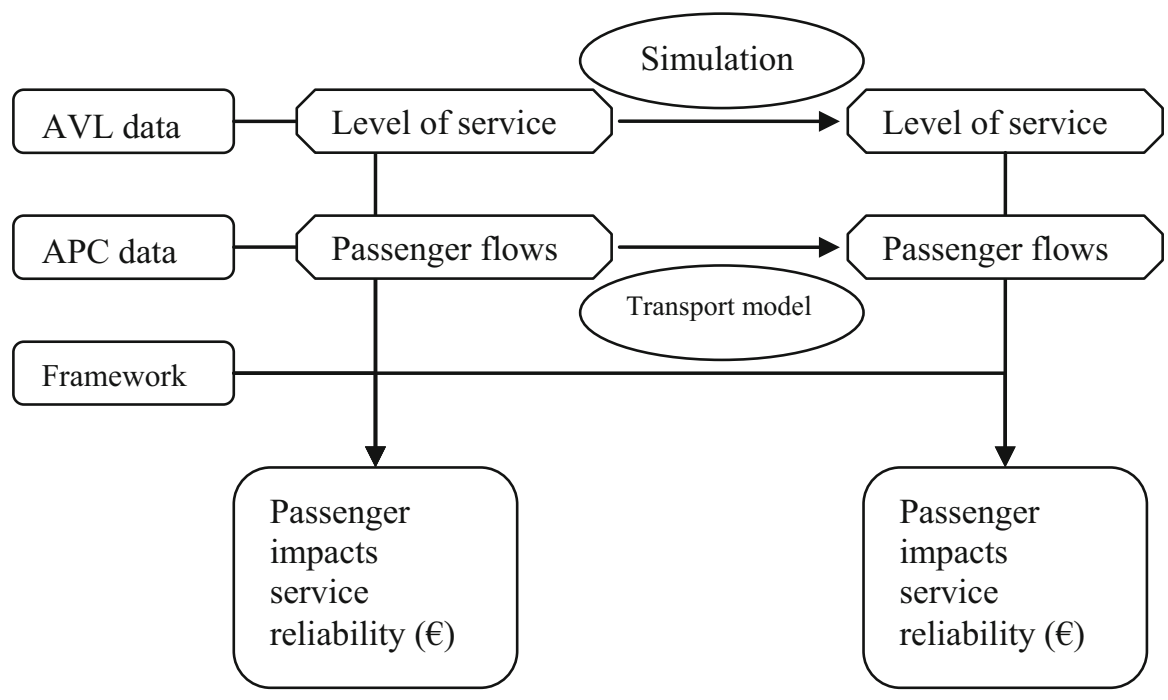

Fig. 8 Calculation steps towards service reliability impacts per case in 2020 
We calculated the passenger effects concerning the change of waiting times and the change of distribution of total travel times. For these calculations we used AVL data of the existing bus services. Future demand of this connection was provided by the transport model of the region, applying the Zenith assignment method of Omnitrans (Brands et al. 2014). Applying the simulation method similar to the one described in Van Oort (2011) we simulated the new operations, yielding the new (distribution of) trip times, dwell times, delays and the level of bunching. The simulated AVL and APC data enabled us to calculate the passenger effects (both extension and variation of travel times). In the reference case, the level of service will be very low due to high passenger demand and insufficient bus infrastructure. In case of the tram line, sufficient infrastructure is provided and tram services require fewer vehicles thereby reducing the probability of bunching. Table 2 summarizes the details of the (expected) level of service in the investigated cases (step 1 of our framework shown by Fig. 5). The level of irregularity is expressed as the average deviation of the headway as a percentage of the scheduled headway. These numbers show a poor level of reliability in 2008 , which will even decrease substantially in the reference case.

In the following step (step 2 of our framework shown by Fig. 5), we calculated the passenger impacts: the average additional travel time per passenger and the distribution of travel times, as shown in Table 3. The additional travel time consists of additional waiting time (calculated by Eq. 2) and the additional in-vehicle time (which is equal to the additional trip time shown in Table 2). For the calculation of the distribution of the waiting and in-vehicle times we applied equations introduced in Sect. 2 and the simulated AVL data. Due to the high level of service reliability in the tram case, the negative passenger effects of unreliability are small. However, due to random arrivals of passengers, there is variation in waiting time. Relative to the total travel time this is limited.

The investigated reference case shows a very poor level of service reliability, which implies that passengers may have to wait for a second or third bus during a short period in the rush hour. Since it only concerns a small group of passengers during a short period, we decided not to adjust the framework concerning the assumption about passengers boarding the first bus. What we did was calculating the impacts of this phenomenon separately from the framework and incorporating the findings in the results of all average passengers. We performed an expert judgement to assess the exact impact, taking into account the available data on actual headway distributions and passenger countings. The reason for an expert judgement instead of a calculation is that the exact passenger processes are not completely clear. Some

Table 2 Actual and expected level of service

\begin{tabular}{llll}
\hline & 2008 & Reference case & Tram case \\
\hline Level of irregularity (\%) & 100 & 150 & 10 \\
Coefficient of variation (CoV) & 1 & 1.5 & 0.1 \\
Average additional trip time (delays per trip) (min) & 1.5 & 2 & $\approx 0$ \\
Distribution of trip time (standard deviation) (min) & 1.5 & 2 & $\approx 0$ \\
\hline
\end{tabular}


Table 3 Passenger effects of unreliability of services in reference and tram case

\begin{tabular}{lll}
\hline & $\begin{array}{l}\text { Reference } \\
\text { case }\end{array}$ & $\begin{array}{l}\text { Tram } \\
\text { case }\end{array}$ \\
\hline $\begin{array}{l}\text { Average additional waiting time per passenger due } \\
\text { to unreliable services (min) }\end{array}$ & 2.9 & $\approx 0$ \\
$\begin{array}{l}\text { Average additional travel time per passenger due } \\
\quad \text { to unreliable services (min) }\end{array}$ & 4.9 & $\approx 0$ \\
\begin{tabular}{l} 
Distribution of travel times (standard deviation) (min) \\
\hline
\end{tabular} & 2.4 & $\approx 0$ \\
\hline
\end{tabular}

Table 4 Additional costs and benefits of tram line compared to reference case (Ecorys 2011)

\begin{tabular}{ll}
\hline & $\begin{array}{l}\text { Value compared to } \\
\text { reference case (millions in 2011) }\end{array}$ \\
\hline Investment costs & $€ 222$ \\
Operating costs & $€ 66$ \\
Total costs & $\mathbf{€ 2 8 8}$ \\
Additional ticket revenues & $€ 40$ \\
Increased travel time & $€ 67$ \\
Service reliability effects & \\
Less waiting time & $€ 123$ \\
Reduction in distribution & $€ 78$ \\
Increased probability of finding a seat in the vehicle & $€ 4$ \\
External effects (emissions, safety, etc.) & $€ 8$ \\
Total benefits & $\mathbf{€ 3 3 6}$ \\
Benefits-costs & $\mathbf{+ 6 4 8}$ \\
Benefit-cost ratio & $\mathbf{1 . 2}$ \\
\hline
\end{tabular}

people, for instance, will try to board the first bus, but while doing that, they see it is overcrowded and they will decide to walk to the second arriving bus. Doing this, they will disturb the passenger flows affecting total boarding time of the first bus. At this moment we do not exactly understand all these parallel processes in detail, which makes calculating impossible. Trozzi et al. (2013) presents new insights concerning this topic, filling in the gap in existing literature of strategy-based assignment. However, that research deals with alternative routes. Further research on this topic will support the extension of the framework presented in Sect. 2.

After the calculation of these passenger impacts, the monetary values of these effects were calculated (step 3 of our framework shown by Fig. 5), using values of time and values of reliability as shown by Table 1 . Table 4 shows the total costs and benefits of the project (Ecorys 2011), showing the substantial contribution of improved reliability to the positive score of the CBA, which is 1.2 (i.e. the benefits are $20 \%$ higher than the costs). The impact of less additional waiting time due to enhanced service reliability of the tram line is $€ 123$ million (calculated over the complete life cycle) and the reduction of distribution in travel time results in $€ 78$ 
million less societal costs. So, service reliability related benefits account for $2 / 3$ of the total project benefits of $€ 336$ million.

Since the CBA result was 1.2, the Dutch Minister of Infrastructure and Environment supported the project with $€ 110$ Million. Without the presented framework presented in Sect. 2, it would not have been possible to calculate the benefits of enhanced service reliability, which proved to be a major part of the total benefits.

\section{Conclusions}

In this paper we demonstrated how to calculate the passenger impacts of service unreliability and how to incorporate them into a CBA. We introduced a three-step framework. We showed that passengers are affected by longer waiting times and the distribution of travel times. In the Netherlands, service reliability is not explicitly incorporated in CBAs, although improved service reliability is often one of the main contributions of public transport projects. In an actual case, the replacement of a bus line by a tram line in Utrecht, we proved that our framework concerning calculating benefits of service reliability is valuable and can be applied into practice. By calculating the benefits of the improved service reliability of the proposed tram line, which were about $2 / 3$ of all expected benefits, the cost benefit ratio was positive. This convinced the Dutch Minister of Infrastructure and Environment to support the project with $€ 110$ million.

The calculated service reliability impacts were substantial and made the difference between a positive or negative business case.

Although the framework yields valuable results, we recommend further investigation on extending the model. The main extension would be taking into account the crowding impact on passenger waiting time. Due to unreliable and crowded services, passengers may not be able to board the first vehicle, which extends their waiting time. In our case, we did an additional calculation to assess these impacts, but further research will be applied to add this phenomenon to the framework. The second recommendation for further research is the behaviour of passengers and their expectation of their travel time. New IT developments as smart phones and planner apps have certainly changed these expectations in recent years.

Open Access This article is distributed under the terms of the Creative Commons Attribution 4.0 International License (http://creativecommons.org/licenses/by/4.0/), which permits unrestricted use, distribution, and reproduction in any medium, provided you give appropriate credit to the original author(s) and the source, provide a link to the Creative Commons license, and indicate if changes were made.

\section{References}

Abdel-Aty MA, Kitamura R, Jovanis PP, Vaughan K (1994) Investigating of criteria influencing route choice: Initial analysis using revealed and stated preference data, Research Report UCD-ITS-RR94-12. Institute of Transportation Studies, University of California, Davis

Annema JA, Koopmans C, van Wee B (2007) Evaluating transport infrastructure investments: the Dutch experience with a standardized approach. Transp Rev 27(2):125-150 
Bates J, Polak J, Jones P, Cook A (2001) The valuation of reliability for personal travel. Transp Res Part E 37:191-229

Besseling P, Groot W, Verrips A (2004) Economische toets op de Nota Mobiliteit, CPB, Document 65, The Hague (in Dutch)

Bos E (2013) Reizen met de tijd mee, B.Sc. Thesis NHTV/Goudappel Coffeng (in Dutch)

Brands T, de Romph E, Veitch T, Cook J (2014) Modelling public transport route choice with multiple access and egress modes. Transp Res Proc 1:12-23

Bunschoten T, Molin E, van Nes R (2013) Tram or bus; does the tram bonus exist? European transport conference

De Cea J, Fernandez E (1993) Transit assignment for congested public transport systems: an equilibrium model. Transp Sci 27(2):133-147

Delgado F, Munoz JC, Giesen R (2012) How much can holding and/or limiting boarding improve transit performance? Transp Res Part B Methodol 46(9):1202-1217

Ecorys (2011) CBA Uithoflijn, Results report (in Dutch)

Frumin M, Uniman D, Wilson NHM, Mishalani R, Attanucci J (2009) Service quality measurement in urban rail networks with data from automated fare collection systems. In: Proceedings of CASPT conference, Hong Kong

Furth PG, Muller THJ (2009) Optimality conditions for public transport schedules with timepoint holding. Public Transp 1:87-102

Goudappel Coffeng (2011), Demand forecasting and service reliability analysis Uithoflijn Utrecht (in Dutch)

Heap RC, Thomas TH (1976) The modelling of platooning tendencies in public transport. Traffic Eng Control 8(9):360-362

Hensher DA, Rose JM, Collins A (2011) Identifying commuter preferences for existing modes and a proposed metro in Sydney, Australia. Public Transp Plann Oper 3(2):109-147

Johanssen PO (1991) An introduction to modern welfare economics. Cambridge University Press, Cambridge

Kanacilo EM, van Oort N (2008) Using a rail simulation library to assess impacts of transit network planning on operational quality. In: Allen J, Arias E, Brebbia CA, Goodman CJ, Rumsey AF, Sciutto G, Tomii N (eds) Computers in railways XI. WIT Press, Southampton, pp 35-44

Kurauchi F, Bell MGH, Schmöcker J-D (2003) Capacity constrained transit assignment with common lines. J Math Model Algorithms 2(4):309-327

Lee A, van Oort N, van Nes R (2014) Service reliability in a network context. Transp Res Rec 2417:18-26

Li Z, Hensher DA, Rose JM (2010) Willingness to pay for travel time reliability in passenger transport: a review and some new empirical evidence. Transp Res Part E 46:384-403

Li Z, Hensher DA, Rose JM (2013) Accomodating perceptual conditioning in the valuation of expected travel time savings for car and public transport. Res Transp Econ 39:270-276

Liu R, Sinha S (2007) Modelling urban bus service and passenger reliability. In: Proceedings of Instr 2007 conference, The Hague

Noland R, Polak J (2002) Travel time variability: a review of theoretical and empirical issues. Transp Rev 22:39-54

Noland R, Small KA (1995) Travel time uncertainty, departure time and the cost of the morning commute. In: Proceedings of 74th annual meeting of Transportation Research Board, Washington D.C.

O'Flaherty CA, Mangan DO (1970) Bus passengers waiting time in central areas. Traffic Eng Cont 11:419-421

OECD/ITF (2009) Improving reliability on surface transport networks

Osuna EE, Newell GF (1972) Control strategies for an idealized public transport system. Transp Sci 6(1):52-72

RAND Europe and AVV (2005) The value of reliability in transport: provisional values for The Netherlands based on expert opinion, Leiden/Rotterdam

Rietveld P, Bruinsma FR, van Vuuren DJ (2001) Coping with unreliability in public transport chains: a case study for Netherlands. Transp Res 35A:539-559

Schmöcker JD, Bell MGH (2002) The PFE as a tool for robust multi-modal network planning. Traffic Eng Control 44(3):108-114

Seddon PA, Day MP (1974) Bus passengers waiting times in greater Manchester. Traffic Eng Cont $15: 422-445$ 
Snelder M, Tavasszy LA (2010) Quantifying the full reliability benefits of road network improvements. In: Proceedings of WCTR 2010, Lisbon

Trozzi V, Gentile G, Bell MGH, Kaparias I (2013) Dynamic user equilibrium in public transport networks with passenger congestion and hyperpaths. Transp Res Part B 57:266-285

Tseng YY (2008) Valuation of travel time reliability in passenger transport, PhD Thesis. Vrije Universiteit, Amsterdam

Turnquist MA, Bowman LA (1980) The effects of network structure on reliability of transit service. Transp Res Part B 14:79-86

Uniman D (2009) Service quality measurement using afc smart card data-a framework for the London underground, Master Thesis. MIT, Boston

Van Der Waard J (1988) The relative importance of public transport trip time attributes in route choice. In: Proceedings PTRC, London

Van Oort N (2011) Service reliability and urban public transport design, T2011/2, TRAIL PhD Thesis Series, Delft

Van Oort N (2014) Incorporating service reliability in public transport design and performance requirements: international survey results and recommendations. Res Transp Econ 48:92-100

Van Oort N, van Nes R (2009) Regularity analysis for optimizing urban transit network design. Public Transp 1(2):155-168

Van Oort N, Boterman JW, van Nes R (2012) The impact of scheduling on service reliability: trip-time determination and holding points in long-headway services. Public Transp 4(1):39-56

Van Oort N, Sparing D, Brands T, Goverde RMP (2015) Data driven improvements in public transport: the Dutch example. Public Transp 7(3):369-389

Welding PI (1957) The instability of a close interval service. Oper Res Q 8(3):133-148 